\title{
Infiltrações e Permanências do cinema
}

\section{Sylvia Beatriz Bezerra Furtado e Érico Araújo Lima}

\section{Resumo}

0 artigo estabelece relações entre filmes de Jonas Mekas, notadamente em Reminiscência de uma Viagem à Lituânia e Walden, Lost, Lost, Lost e os Rolos, de Ivo Lopes, e Supermemórias, de Danilo Carvalho, tentando criar conexões e atualizações de uma proposição que antes de ser apenas uma defesa do cinema como lugar de retenção de fragmentos da vida, faz a própria defesa do cinema. Ao aproximar cinemas, eles todos feitos de pequenos fragmentos, o que surge são trânsitos de um filme sobre 0 outro e a permanência do próprio cinema. Para tal, toma a tese da sobrevivência das imagens como fundamento teórico, nos termos elaborados por Didi-Huberman.

\section{Palavras-Chave}

Jonas Mekas. Memória. Películas. Cinema Contemporâneo.

\section{Sylvia Beatriz Bezerra Furtado}

I sylviabeatrizbezerrafurtado@gmail.com Profa. Dra. Beatriz Furtado é do Programa de Pós-Graduação em Comunicação, da Universidade Federal do Ceará. É autora de "Imagens Eletrônicas e Paisagem Urbana" e "Imagens que Resistem- a imagemintensidade no cinema de Sokurov" e organizadora da coletânea "Imagem Contemporânea", volumes I e II.

Érico Araújo Lima I ericooal@gmail.com Mestrando no Programa de Pós-Graduação em Comunicação da UFC. Integrante do Laboratório de Estudos e Experimentações em Audiovisual (LEEA-UFC).

\section{Introdução}

A câmera Bolex foi para Jonas Mekas um jeito de conter a vida, armazená-la em fragmentos. Exilado, sem país, sem família e sem o diário que havia escrito por mais de dez anos, Mekas fez do cinema um reservatório, lugar de invenção e de retenções. Um ridículo gesto, diz o próprio Mekas, cinquenta anos depois, uma vez que ele mesmo se diz em estado de desaparecimento.

Essa vontade de guardar a vida, seus fragmentos preciosos, sempre pautou o debate sobre a imagem, a história das imagens é sempre sobre 0 que elas são capazes de conter, mas é, sobretudo, uma pergunta continuada sobre o que faz a permanência do próprio cinema. Uma pergunta que inquieta também Ivo Lopes, responsável pela fotografia de mais de vinte dos filmes da mais recente produção nacional, e que há cinco anos vem fazendo seus "Rolos", pequenos filmes sobre pedaços de sua vida entre a família e os amigos. Desde o Rolo 1, de 2009, vê-se no trabalho de Ivo Lopes o exercício do cinema, do rosto, da paisagem, das diferenças de luz, os movimentos e os ritmos da imagem. 
São filmes sobre o inelutável do fazer cinema, a permanência desse fazer, a vontade de se encontrar próximo à câmera, de ver o mundo, seus objetos e seus habitantes, como imagem, de abrigar sob o olhar essa transparência das lentes, como elas reagem aos encontros, como faz explodir o mundo em luminosidades ou como 0 apaga completamente quando se perde da luz. Ivo Lopes reatualiza os gestos de Mekas, esses gestos cinematográficos que diretor, nos seus passados 91 anos, continua a inventar. Mekas, este que tomou o cinema como condição de vida e que 0 fez atravessar os duros períodos das grandes guerras, ocupações, genocídios, campos de trabalho forçado e a relutância da imagem que restou do pai jogado contra o muro, fuzil nas costas, continua a fazer do cinema as estripulias que retira dessa intimidade visceral com a câmera, seus deslocamentos intempestivos, suas imagens surpreendidas pela luz que atravessa o quadro, seus encontros com o qualquer transformados em monumentos.

Já Danilo Carvalho, embora não faça imagens, uma vez que se apropria dos fotogramas em Super8, desgastados pelo tempo e pelo abandono, o gesto cinematográfico que interessa é aquele modo Mekas de se distanciar de seus próprios trabalhos, por muitos anos, uma dezena deles, sem que haja um trabalho de montagem, sem que se transforme em filme, além do imenso gosto pelo trabalho com os rolinhos de filmes. É esse distanciamento do tempo, que em Mekas é recorrente em relação ao seu próprio material, que em Danilo Carvalho se faz pelo desconhecimento mesmo do que foi filmado. Gesto esse que faz com que em Supermemórias não se possa distinguir onde começam as imagens e os sons de um de outro dos realizadores dos filmes. São os próprios rolinhos da família de Danilo Carvalho que se misturam a centenas de fragmentos de outros rolinhos de outras famílias. É, talvez aqui, que se explique bem a defesa que Mekas faz sobre esse espaço mínimo da passagem entre o que é pessoal e o que é universal, quando evoca uma carta de um jovem escritor dirigida a Dostoiévsky, em que diz tentar ser muito universal, mas que tudo acaba ficando muito parecido com ele, muito pessoal, questão para qual "o senhor Dostoiévsky responde: para ser universal você tem que ser muito, mas muito mesmo pessoal, e é essa a coisa mais difícil". (GOMES, 2011).

\section{Mekas e a memória}

A invenção do cinema de Mekas parece, dessa forma, apontar para 0 anacronismo das imagens, exatamente como defende Didi-Huberman (2000) em suas teses sobre a sobrevivência das imagens como um regime que lhes constitui. Os filmes de Mekas não são o retorno de sua vida perdida, como às vezes ele mesmo se deixa explicar, embora exista uma presença ativa desse deslocamento. Trata-se de um cinema que se inventa nesse deslocamento, que se faz como uma presença ativa, mas que, no entanto, não lhe é devedor, menos ainda uma representação do passado. Tomando a tese de Didi-Huberman 
da sobrevivência das imagens, é possível dizer não de um cinema que tem na memória do exílio sua potência de invenção, mas de como Mekas trabalha com os tempos impuros dessas imagens.

Didi-Huberman fala de regimes temporais diversos onde 0 anacronismo se instaura como um paradoxo. Para tal, Didi-Huberman evoca um tipo de memória em que pressupõe a sobrevivência (Nacheleben) e que teria transformado toda proposição da passagem do tempo. A sobrevivência então passa a ser uma espécie de memória inconsciente, ela desorienta as relações de antes e depois, seu ritmo está submetido aos poderes do após-golpe e do retorno do repelido, onde a configuração do tempo ocorre em movimentos invisíveis que sobrevivem e que aguardam o momento, sempre inesperado, de se manifestar subitamente. Tempo que impõe uma desorientação temível para qualquer periodização.

Já não se trata de um rio contínuo, no qual as coisas seriam simplesmente transmitidas da cabeceira para a foz, mas de uma dialética tensa, um drama encenado entre 0 curso do rio e seus próprios redemoinhos (DIDI-HUBERMAN, 2013, p. 76).
Filmes de Mekas são anacronias ${ }^{1}$ de si mesmos, dimensões superpostas, reflexos cruzados de um é e já não mais e ao mesmo tempo distintos planos. Dessas temporalidades cruzadas, costuma-se dizer de um espaço de tempo real, ou seja, suas imagens filmadas diretas, ao mesmo tempo de como ela acontece às nossas percepções dos movimentos ininterruptos do tempo. Mas o cinema não apreende, em imagens e sons, sequer um fragmento dessa passagem, do decorrer das coisas do mundo. Assim, Mekas é um artesão do que pode a imagem inscrever sobre a luz, as paisagens, os rostos, as passagens, os objetos, 0 vento, 0 balanço, como imagem em suas condição precária. Daí essa percepção dos filmes como a memória, uma imagem que não se fixa, que não se deixa aprender, que escapa das mãos, da vista.

São gestos cinematográficos: súbitos deslocamentos da câmera em direção a uma pessoa, uma luz que corta o espaço entre as árvores de um parque. Um gesto cinematográfico de pouco pousar o olhar na sua forma contemplativa mesmo quando, por exemplo, são longos minutos sobre o caminhar de uma jovem num parque: seu corpo é percorrido por movimentos contínuos para cima, para baixo;

Em A Imagem sobrevivente (2013, p. 107-126), Didi-Huberman fala de uma sismografia dos tempos moventes, de um jogo temporal das latências e crises, onde teria se configurado a metáfora geológica, bem inquietante: as vagas, as ondas de memória, que afetam e atravessam um elemento, que nada tem de fluido. Assim tomarmos esse princípio instaurador do tempo e a configuração dele decorrente de uma ideia de memória, toda explicação, bastante corrente de que a obra cinematográfica de Jonas Mekas estaria pautada especialmente pelo fato dele ser um exilado lituano do pós-guerra, embora seja da mais extrema importância, não explica a sua verve inventiva, a potência do seu cinema e nem mobiliza o pensamento para além do modelo paradigmático da imagem como representação. Aqui importa saber o que faz Mekas quando faz cinema. E não simplesmente, dizer que no Rolo x, do filme Lost, Lost, Lost, há um momento sombrio porque sua vida estava sombria. 
um quadro mais fechado; uma câmera fixa que a deixa afastar-se; um perfil coberto por uma sutil contraluz. A demora é uma busca sempre em cortes, em aproximações e afastamentos. As imagens de um casamento são menos solene que agitada pelos movimentos da câmera sobre as pessoas, a cerimonia, a saída da igreja, todas imagens como pequenos lampejos. Cenas que são montadas durante a filmagem, dado que no material bruto não é possível conseguir esse tipo de resultado. São singles-frames que apenas a câmera Bolex consegue produzir.

São imagens que ficam muito pouco, que se perdem em meio aos movimentos do próprio olhar, que parecem querer coincidir com o seu piscar ou produzir na imagem esse interregno entre um abrir e um fechar os olhos de forma involuntária. Esse estatuto das imagens de Mekas aponta para o cinema tanto quanto para o mundo. Filmes que parecem invocar o quanto o cinema é capaz de dialogar com o mundo das coisas, das pessoas, dos acontecimentos. Os filmes estão sempre dizendo em imagens como o cinema se aproxima através das lentes da câmera, como ele se afasta com o movimento de distanciamento do corpo que a porta e como se afasta do objeto filmado no seu movimento inverso. Mekas faz com que a câmera seja parte de si. Mekas tem uma relação com a câmera que resulta do contato cotidiano, um estado de atenção com o mundo a ser filmado que é uma conquista que se faz ao longo dos anos e também pelo que a Bolex oferece de filmar imediatamente, reagindo a cada olhar. "[...] levou muitos anos para que eu pudesse dominar esta câmera, para que ela se tornasse uma extensão dos meus dedos, do meu corpo, de forma que eu não precise nem pensar para operá-la. É esse tipo de estado que se precisa atingir" (GOMES, 2011).

Mas não é somente na câmera, esta que 0 tempo todo acompanha o ritmo do seu olhar, que 0 seu cinema se diz cinema. A montagem também se exibe como um jeito de abrigar no filme essa experiência do ver com todo o corpo, com todos os seus sentidos. Mekas monta com muitas sobreposições de imagens, aproximando-as de outras imagens já sobrepostas nos vidros, nos espelhos e nos objetos translúcidos que deixam as imagens se atravessarem. Um tipo de montagem cujas ações não se dão simultaneamente pelo artifício de um paralelismo, nem se dão justapostas para alcançar um pensamento síntese, por exemplo. Talvez o caleidoscópio, esse aparelho ótico que permite combinações variadas de fragmentos de imagens, possa ser uma referência para organização das imagens em Mekas, mas quem sabe se possa dizer melhor pelas luzes dos pirilampos, esse vagalumes que no escuro se acendem por amor ao outro, enfeitiçados que estão por algum parceiro. Mekas se enfeitiça com o mundo e a ele se dirige pela imagem do cinema.

Há também um dado importante do processo de filmar e da montagem em Mekas que talvez possa dizer sobre como seu cinema se constitui. Em um texto intitulado O filme-diário (1972), Mekas diz como seu cinema acabou se constituindo 
como notas, pois que filmava com o tempo que lhe restava de outras atividades, aproveitando pedaços de películas, apenas podendo ver 0 material filmado, no caso do que produziu a partir de 1949, por volta de 1961/1962. "Ao ver aquele material antigo, notei que havia várias conexões nele. As sequências que considerava totalmente desconectadas de súbito começaram a parecer um caderno de notas com muitos fios unificadores, mesmo naquela forma desorganizada" (MEKAS; MOURÃO, 2013, p. 132). Difícil pensar que essas notas pudessem ser entendidas como reflexões sobre 0 apanhado em imagens. Logo Mekas percebe que essas imagens são menos anotações que um exercício de filmar, algo que diz de investigações sobre um modo de filmar, sobre qual velocidade (24, 32 quadros etc.); sobre como essas velocidades afetam à iluminação; sobre qual exposição de luz; sobre como a câmera reage às condições da cena, quais são suas impossibilidades.

Se mesmo assim, ainda é possível falar de imagens-memória, como algo que impele o cinema de Mekas como uma força do absolutamente necessário para filmar, por outro só podemos acessar esse cinema se de memória falarmos, em termos de Deleuze (1990), como lençóis de tempo. ${ }^{2}$ Algo que se pode observar nos varais de roupas que aparecem ao vento, pendurados entre janelas, em Lembranças de uma Viagem à Lituânia (82', 1972), quando as imagens parecem subtrair as marcas temporais, mesmo que o filme seja feito de camadas dessas marcas: são três partes que vão dos anos de chegada à Nova Iorque a uma segunda parte da viagem à Lituânia, após vinte anos de partida e, uma última parte, que diz de uma passagem por Elmshorn, em Hamburgo, na Alemanha, lugar onde Mekas e Adolfas, seu irmão, passaram um ano no campo de trabalho forçado durante quatro anos da guerra.

Esse filme repartido em períodos dá-se a ver como mundos embaralhados pelo cinema. As imagens são esses tempos múltiplos sempre, mesmo quando montado em uma sequência. 0 cinema monta, mas não isola essas partes. As aproxima. Por trás das imagens, das palavras, dos ruídos e das músicas de "Lembranças de uma Viagem à Lituânia" não está uma memória de três tempos, não nesse sentido cronológico em que foi montado. Estão nas imagens todas essas memórias, de diferentes tempos, na forma de cinema. A memória é ela mesma as imagens, 0 filme. Estamos diante do filme como experiência. Na perspectiva que nos ensina Didi-Huberman,

Gilles Deleuze (1990, p. 103) em seus escritos de cinema corrobora com as teses de Henri Bergson sobre a coexistência do tempo passado com o presente que ele foi e de que o passado se conserva em si, como passado em geral (não cronológico): 0 tempo se desdobra a cada instante em presente e passado, presente que passa e passado que se conserva", mas, diz Deleuze, cada vez mais, ele (Bergson) dirá algo bem diferente: "a única subjetividade é o tempo, o tempo não-cronológico apreendido em sua fundação, e somos nós que somos interiores ao tempo e não o inverso. Que estejamos no tempo parece um lugar-comum, no entanto é um paradoxo. 0 tempo não é interior em nós, é justamente o contrário, a interioridade a qual estamos, nos movemos e mudamos". 
quando em Devant l'Image (1990) e Devant le Temps (2000), diz sobre o olhar (regarder) como uma experiência que necessitamos a cada vez refunda-la, reconstruir suas fundações.

De outro, nessa linha de pensamento em que Didi-Huberman segue os passos do historiador alemão Aby Warburg (1866/1929) as imagens são entes migratórios, fantasmas capazes de atravessar todas as fronteiras, e é nesse sentido que o reino de Cronos se abre ao que não se pode ordenar. 0 que significa dizer que à luz do anacronismo, da exuberância temporal das imagens, o passado não pode ser mais considerado como uma coisa exata, ele é atravessado pelas sobrevivências, porta uma memória e articula agenciamentos temporais que o excedem. É mais que uma memória de agenciamentos impuros, de montagem não histórica do tempo. É a própria história que já não pode ser considerada como uma ciência exata, mas uma poética, uma montagem não científica do saber.

Assim, é possível dizer que as camadas temporais articuladas em três períodos em Lembranças de uma Viagem à Lituânia são grupos migratórios das reminiscências de si mesma. Não por acaso, Mekas tem com este filme uma relação bem particular em relação a sua obra cinematográfica, evocando o uso da palavra como em quase nenhum outro filme. Lembranças de uma Viagem à Lituânia tem uma abundância narrativa, quando em outros filmes seus o que se vêé a ação silenciosa ou, no mais das vezes, apenas pequenas pontuações feitas pelo texto em voz off, dito pelo próprio Mekas, ou por cartelas ou curtos textos. Há neste filme uma vontade acentuada de narrativa, que aparece como uma espécie de concessão dentro do seu trabalho. No entanto, é justo esse imperativo narrativo que faz notar essa impossibilidade de a estrutura narrativa se constituir apenas como uma estratégia possível para o fazer cinema. Lembranças... escapa ao controle da estrutura fílmica.

É exemplar o segmento mais longo do filme, quando Mekas faz uma colagem de cenas ordenadas por números, que parecem contribuir com uma lógica narrativa, e o que ocorre na imagem são desequilíbrios, produzidos pelas variações de luminosidade que geram descontinuidades, fragmentações espaçotemporais. Numa das cenas, a câmera faz um círculo na vertical, uma imagem vertiginosa. Em seguida, vem o fogo alto da fogueira que toma todo o plano, queima na imagem. Em outro momento, pedaços de uma mesma cena, que se repete várias vezes, em que um homem faz uma fotografia em direção ao fora de campo. Logo adiante, uma família pousa para a fotografia, cada um deles com uma flor vermelha mas mãos, a família posa. A câmera faz um close na flor, se afasta. Uma nova pose, agora entre os membros da família Mekas, a cena das medidas, onde eles se põem numa forma em que a mãe, ao centro, é ladeada no quadro, primeiro entre os dois menores e nas pontas pelos dois homens maiores. Logo mais, outras medidas, 
outras pessoas, outras composições definidas pelo tamanho, cuja medição se faz com uma vara de madeira sobre as cabeças. As medidas vão sendo anotadas, para cada um a medida que lhe corresponde e 0 seu nome anotado ao lado, registro que se faz numa parede.

Mais que de lembranças de uma viagem, trata-se de um filme em busca de encontros, com a família, os vizinhos, os lugares. Um filme cujas ações são performatizadas para a cena, onde essas cenas são construídas para 0 cinema, para virar imagem. Mekas tem muita consciência disso, ele dirige a cena, ele narra e, finalmente, ele diz: "agora meu passado existe". Existe como cinema. Em geral, os filmes de Mekas são com os amigos. Ações de um cineasta em volta do mais próximo, mas, principalmente, são filmes realizados como uma forma de vida, conversações sobre si. 0 cinema de Mekas vem da potência do inenarrável desses encontros entre os seus, encontros esses que 0 seu próprio cinema produz, e que é ao mesmo tempo uma espécie de acolhimento do mundo.

Mas não todo o mundo, apenas uma parte dele, aquele que se encontra ao seu redor, a sua própria vida, que ocorre muito mais na condição de invenção que propriamente na de relato. Inventar o cinema em lapsos de tempo, com o tempo que lhe restava, aproveitando pedaços de películas, sem ver o material filmado imediatamente, filmando como um exercício, fazendo desse filmar um modo de não perder a proximidade com a câmera. Árvores, ruas, neves, parques, objetos recorrentes dos filmes de Mekas, definem imagens de uma câmera Mekas, são árvores, ruas, neves e parques feitas pelo choque das luminosidades, pelas superexposições como pontuações, são imagens feitas de uma luz que impregna o mundo a uma só vez de uma proximidade e de uma distância, pois que um cinema de composições.

\section{Rolos, Supermemórias e Mekas}

É também do encontro com o familiar e com os problemas do próprio cinema que os Rolos, de Ivo Lopes, uma obra composta de pequenos filmes continuados, são atravessados pela obra de Mekas. Rolos trabalha com a imagem impura, com o riscado de pontas de películas, para celebrar uma série de encontros com os amigos, em especial os que se juntam pelas afinidades com o cinema, por aquilo que o cinema permite de reunião entre aqueles que o produz como quem vive. Rolos é uma espécie de filme que Ivo Lopes faz quando estar entre os seus, para olhar o seu arredor, para ficar mais próximo da câmera como matéria de criação. É um cinema que é sobre o fazer filmes com pequenos rolos de película, em que cada um deles é um fragmento de um contínuo, um trabalho continuado.

Os trabalhos de Ivo Lopes e de Danilo Carvalho são parte de um processo de produção de filmes coletivos e que tomou a forma de uma produtora, a "Alumbramento", formada por pessoas, na sua maioria, ligadas, de alguma maneira, à primeira turma da Escola de Audiovisual, da Vila das Artes, 
em Fortaleza. As relações entre os que fazem a "Alumbramento" são totalmente costuradas pelas afinidades com um modo de cinema que só se faz possível porque há um desejo de arte no coletivo. Alumbrados, encantados por fazer cinema, desejosos de oferecer uma Longa Vida ao Cinema Cearense, este é que o título do curta dirigido pelos Irmãos Pretti, que formula uma proposição de cinema a partir de uma citação de Ezra Pound, "Curiosidade. Conselho aos Jovens. Curiosidade".

Da escola do audiovisual, às ruas do prédio Dona Bela, edifício no Centro de Fortaleza onde vivem as muitas e variadas famílias da Alumbramento, ao Alpendre, uma casa de arte que abrigou outro grupos de amigos em torno das artes, o filme Longa Vida...., parece indicar os caminhos desse cinema da mais nova geração de cineastas, cuja repercussão dos trabalhos pode ser vista na Mostra de Cinema de Tiradentes, em Estrada para Ythaca, dos Irmãos Pretti e Primos Parente; nas páginas do Cahiers do Cinéma; na DocTV, Sábado à Noite, de Ivo Lopes, ou na circulação do irreverente Doce Amianto, de Guto Parente e Uirá dos Reis.

Esse tipo de ação coletiva, que resulta nesses cinemas parece estabelecer um diálogo direto com os movimentos de muitas gerações de outros cinemas, em especial, aquele que Mekas deu a conhecer, ao apresentar em 1962, no Film Culture, nos números 21 e 24, suas notas sobre o Cinema da Nova Geração Americana, quando explica que essa produção não será lembrada, ao contrário do que pensavam os críticos de cinema da época, como os que lutaram contra Hollywood. Mekas estava nesse momento tentando reverter uma ideia, ainda hoje bastante recorrente, de que esse cinema produzido pelas jovens gerações, com baixo orçamento, com equipes reduzidas e com um enorme esforço inventivo, teriam como legado apenas o desejo manifesto contra a grande indústria cinematográfica norte-americana.

[...] Como os experimentadores, os cineastas de 'fluxo da vida' não se reuniram para lutar contra Hollywood. Eram indivíduos únicos, que pacificamente, tentavam expressar a sua própria verdade cinematográfica por seu próprio tipo de cinema. É desnecessário dizer que, do ponto de vista estético, eles estavam descontentes com 0 estilo de Hollywood e os temas tratados. Em seus filmes, queriam romper o círculo fechado de 'cinema como profissão'. Queriam fazer filmes mais pessoais. [...] Os pequenos orçamentos, as equipes reduzidas, e o lado visualmente e tecnicamente brutos, dadas as condições de filmagens novas e imprevisíveis, empuseram aos cineastas liberar seu trabalho das formas visuais e dramáticas convencionais, assim como também os forçou a buscar novos ângulos, e sob uma nova luz ${ }^{3}$ (MEKAS, 2002, p. 23, tradução nossa).

"Comme les experimentateurs, ces cineastes du "flux de vie" ne rassemblèrent pas pour lutter contre Hollywood. C'étaient des individus singuliers qui, de manière pacifique, essayaient d'exprimer leur propre vérité cinematographique, en faisant leur propre sorte de cinéma. Inutile de dire que d'un point de vue esthétique ils étaient mécontents du style d'Hollywood et des sujets traités. Dans leurs films, ils voulaient rompre avec le cercle fermé du "cinéma comme profession.", ils voulaient faire des films de manière plus personnelle. [...] Les petites budgets, les équipes réduites, et le côte visuellement et techniquement brut imposé par les conditions de tournages nouvelles et imprévisibles poussèrent les cinéastes à libérer leur oeuvre des formes visuelles et dramatiques conventionelles, éculées, et aussi les forcèrent à chercher de nouveaux angles, et dans une lumière nouvelle". 
0s cinemas de Jonas Mekas, Danilo Carvalho e Ivo Lopes - e aqui não se trata de fazer simples comparações, mas de desterritorializar esses cinemas para transitar no que a obra de Mekas aciona de novos cinemas - apontam na direção de um projeto estético e político implicado na defesa do próprio cinema. Guardar o cinema da sua condição de desaparecimento. Não propriamente e somente para coletar o mundo, seus pequenos paraísos familiares e amorosos, mas, assim 0 fazendo, guardar o cinema, voltarse para ele. Esse mesmo tipo de gesto que também é assumido por Danilo Carvalho, que em Supermemórias reúne registros caseiros dos anos 1960, 1970 e 1980, realizados por moradores de Fortaleza, transformando esse material em fragmentos de um cinema comum. Uma supermemória em um sentido menos de armazenagem das imagens de cada desses filmes que da defesa do próprio cinema, do Super8, sua continuidade, seu não apagamento.

Desde o primeiro plano de Supermemórias, a contagem dos segundos exibe a matéria fílmica, a passagem da película. Antes do filme de Danilo Carvalho, já haviam as bobinas guardadas em um lugar qualquer, nas casas das pessoas que resolveram atender a convocatória de Supermemórias, mais de 400 bobinas, a maioria com muitos problemas, com mofos, e que foram recuperadas e devolvidas em uma mídia digital. Ficaram os rolinhos de Super8 para formação da matéria a partir da qual Danilo Carvalho passou a trabalhar o seu filme. As bobinas recuperadas foram projetadas em Super 8 na casa de cada um dos que fizeram as doações, momento em que 0 realizador pode também ver todo material bruto que iria trabalhar, mas também um momento de saudação ao cinema, aos encontros que ele acabava por permitir que ocorressem, cena maior de uma sala, um projetor $16 \mathrm{~mm}$, da luz que transitava entre ele e a parede escolhida para a projeção, dos olhos atentos e das interferências das conversas entre um e outro sobre aquele momento, sobre aquela cena e da mistura entre 0 foi e o sendo, movimentos que a memória produz e o puro desconhecimento. Um estado de cinema.

Supermemórias tem essa poética da pequena película, não apenas pela plasticidade com que as marcas do tempo vão se fazendo imprimir em forma de riscos, de pontas apagadas, arranhados dos sons ou pelo tipo de luz que o Super8 produz, mas por fazer referência à construção do olhar, à paisagem, aproximações, distanciamentos dos objetos em cena, a cena da criança que olha a câmera a partir de uma máquina fotográfica analógica, a repetição dos mesmos gestos dirigidos a cena por diferentes pessoas de diferentes bobinas, a experiência com os efeitos da contraluz, as superposições de imagens. E as imagens fantasmagóricas do cinema e as imagens da película queimada em suas formas abstratas, que se recobrem do som envelhecido da fita K-7 de uma velha secretária eletrônica.

Numa das sequências de Supermemórias, aos 12 minutos, um garoto olha para 0 extracampo 
fílmico, e diz: "Começo do filme: Luz, Câmera, Ação!". A partir daí, uma longa sequência em que um grupo de garotos encena um filme de bang bang, lutas corporais, perseguições, assassinato etc. É o filme convocando sempre o modo de fazer cinema, apontando para 0 descontrole da representação, para o que configura uma proposição de mise en scène, fazendo ver 0 cinema como uma forma de estar no mundo. Esse gesto de fazer cinema a partir de uma coleta dos pequenos rolos de Super8, de Danilo Carvalho, é algo da ordem de um cinema de montagem, mas é sobretudo, a reinvenção do cinema de Mekas.

Não por acaso, Danilo Carvalho faz o som de Sábado à Noite, filme de Ivo Lopes. 0 que exatamente Danilo Carvalho e Ivo Lopes decidem fazer quando registram em Sábado a Noite, o que não controlam e o que não conhecem, é menos narrar sobre uma noite de sábado em Fortaleza que extrair o desaparecimento do cinema, deixando disseminar um cinema de retenções. Não mais das mesmas retenções das apostas neorrealistas, dos longos planos nascidos do fluxo do tempo, ainda que esse tipo de plano esteja também em Sábado à Noite, mas fazendo do decorrer do tempo um estado permanente de acompanhamento de pessoas, 0 que fazem, para onde se dirigem, o que olham. Trata-se de filmes com evidentes preocupações estéticas e políticas sobre 0 desenho dos movimentos na paisagem. Um cinema como arte para mover padrões, que experimenta a liberdade da câmara, da montagem intuitiva, e como uma atitude de vida, traços de um mundo sensível, tal como procede Mekas em seus filmes.

Cada um dos Rolos de Ivo Lopes é uma experimentação radical com o cinema em película, com a bitola $16 \mathrm{~mm}$. Se apenas no último ano, Ivo Lopes assinou a fotografia de seis longasmetragens (Quando eu era vivo, de Marco Dutra; Tatuagem, de Hilton Lacerda; O homem das multidões, de Cao Guimarães e Marcelo Gomes; Depois da chuva, de Marília Hughes Guerreiro e Cláudio Marques; O Rio nos pertence!, de Ricardo Pretti; O uivo da gaita, de Bruno Safadi), é em seus pequenos Rolos que se pode perceber uma enorme liberdade com o fazer cinema. Rolos, exercícios livres, são filmes de encontros, de busca por algo que acontece entre a imagem e 0 mundo, entre a cena qualquer e o que a película pode encontrar em suas variações de cor, de luz, de velocidade, de movimento. Um universo sem decupagem, sem raccords, sem eixo. Uma imagem que transita na relação do corpo do fotógrafo com a imagem em movimento, com a câmera na mão.

\section{A primeira montagem de alguns desses "Rolos"} tem por título Desterro Session, resultado de um encontro entre um grupo de amigos que fazem cinema, na fazenda "Desterro", interior do Ceará. Rostos, sorrisos, banhos de açude, conversas, todas em torno do cinema, para fazer cinema, para ver cinema: uma longa sequência, um grande lençol branco estendido na vertical, amarrado em duas árvores e a afinação do projetor para uma das exibições do cair de tarde. Cena que 
configura a história não apenas do mais recente cinema brasileiro, mas notadamente de um jeito de fazer gostar de fazer em meio a um coletivo, para saudar o cinema, sua luz, seus movimentos, sua trajetória, suas inquietações. Permanência e infiltrações de Walden, Lost, Lost, Lost e tantos outros filmes do mestre Jonas Mekas.

Eu quero celebrar as pequenas formas cinematográficas, as formas líricas, os poemas, as aquarelas, os estudos, os esboços, as cartas postais, os arabescos, as conversas, os pequenos cantos em 8mm [...] Nesses tempo onde todos querem conquistar e vender, eu quero celebrar aqueles que sacrificam o sucesso social todos os dias em busca dos invisíveis, do pessoas, coisas que não fazem dinheiro, nem pão [...] Eu sou pela arte que se faz uns com os outros por amizade, por si mesmo (MEKAS, 2001, p. 9, tradução nossa).

É essa permanência do cinema que aparece nos Rolos de Ivo Lopes e no Supermemórias, de Danilo Carvalho, que diz de uma arte que não é nunca apenas uma arte. "É sempre uma proposta de mundo, com procedimentos formais que são quase sempre os restos de utopias que visam à redistribuição das formas de expressão sensível coletiva" (RANCIÈRE, 2012a, p. 49). Também, vale ressaltar, é nesses termos que se pode apreender que 0 que interessa a esse tipo de cinema é a criação de uma forma de vida, tal como Rancière aponta em relação ao projeto cinematográfico de Dziga Vertov como resultado de uma vontade de se constituir como laço comunitário. "Uma arte que se pensa como capaz de criar, por sua prática, o tecido de novas formas de vida" (RANCIÈRE, 2012b).
Reunir Rolos, Supermemórias e os filmes de Mekas, é uma forma de articular espedaçados de imagens e sons que se infiltram uns sobre os outros e reconfiguram ordens de tempos e que ensaiam desconcertantes deslocamentos de contínuos históricos. Entre a permanência e o desaparecimento de modos cinematográficos, entre Mekas e os seus cineastas nos anos 1960 e alguns novos cinemas desses anos 2000, mais que continuidades há infiltrações e desejo de cinema, ininterruptos, que talvez só possam surgir se não houver qualquer renúncia daqueles que vêm de estar em permanente vontade de acompanhalos. Tal como Didi-Huberman (2011) ensina ao falar sobre a força dos vagalumes, afirmando que eles só desaparecem quando há uma renúncia, por parte de quem olha, de fazer o seu próprio deslocamento, porque eles só desaparecem das vistas quando há uma recusa a sair do próprio lugar, este ponto fixo que não é o melhor lugar para vê-los.

Todos esses movimentos de infiltrações e de permanência do cinema são, finalmente, talvez uma das grandes teses das História(s) do Cinema, de Jean-Luc Godard, pois que feita da fragmentação das imagens e da irreverência da submissão do cinema às histórias.

Ao inventar relações inéditas entre filmes, fotografias, pinturas, jornais da tela, músicas etc., a iniciativa de Godard atribui ao cinema, retrospectivamente, o papel de revelador e de comunicador que ele traiu quando se sujeitou à indústria das histórias (RANCIÈRE, 2012a, p. 48). 
Reunir aqui alguns filmes de Jonas Mekas, Ivo Lopes e Danilo Carvalho não é atribuir a eles uma mesma linha de pensamento cinematográfico, não é nem mesmo dizer sobre o que há no cinema de um de outro que possibilite traçar um mesmo universo sensível. Trata-se, sobretudo, de um gesto de colocar sobre uma espécie de mesa de montagem os fragmentos de resistência de uma comunidade de dissidentes e, ao mesmo tempo, é constituir um lugar para pensar o que Robert Bresson (2000, p. 22), em seus cadernos de notas sobre 0 cinema, disse para si mesmo: "dedicar-me às imagens insignificantes (não-significantes)".

\section{Referências}

BRESSON, R. Notas sobre o cinematógrafo. Porto:

Elementos Sudoeste, 2000.

DELEUZE, G. Imagem-Tempo. São Paulo:

Brasiliense, 1990.

DIDI-HUBERMAN, G. Devant Le Temps. Paris:

Minuit, 2000.

DIDI-HUBERMAN, G. Devant l'Image, Questions posées aux fins d'une histoire de l'art, Paris: Minuit, 1990.

DIDI-HUBERMAN, G. Sobreviventes dos Vaga-lumes. Belo Horizonte: UFMG, 2011.

DIDI-HUBERMAN, G. A Imagem Sobrevivente. Rio de Janeiro: Contraponto, 2013.

GOMES, Juliano, em revista Cinética, setembro de 2011, acessada em 09.03.2014, Disponível em: http://www. revistacinetica.com.br/entrevistamekas.htm

\section{MEKAS, J. Déclarations de Paris/Statements from}

Paris, Les Cahiers de Paris Experimental 2, Paris, 2001.

MEKAS, J. Le Cinéma de la Nouvelle Génération.

Paris: Éditions Paris Experimental 8, 2002.
MEKAS, J.; MOURÃO, P. (Org.). Mekas. São Paulo: Centro Cultural do Banco do Brasil, Pró-Reitoria de Cultura e Extensão Universitária da USP, 2013.

RANCIÈRE, J. As distâncias do cinema. Rio de Janeiro: Contraponto Editora, 2012a.

RANCIÈRE, J. Formas de vida: Jacques Rancière fala sobre estética e política. Entrevistador: Guilherme Freitas. 0 Globo, 2012b, Prosa. Disponível em: < http:// oglobo.globo.com/blogs/prosa/posts/2012/12/08/ formas-de-vida-jacques-ranciere-fala-sobre-esteticapolitica-478094.asp > . Acesso em: 08 mar. 2014.

\section{Filmografia}

SUPERMEMÓRIAS. Mais uma memória para uma cidade sem lembranças... Diretor: Danilo Carvalho. Elenco relevante. Local: Produtora, CE/Brasil. 2010. 20min. Disponível em: <www.filmessupermemorias.com.br>

ROLOS. Diretor: Ivo Lopes. Elenco relevante. Local: Produtora, 2009/2014. Disponível em: < http://www. alumbramento.com.br/filmes.php? $\mathrm{p}=$ diarios $>$

DESTERR0 session. Diretor: Ivo Lopes. Elenco relevante. Local: Produtora, data de publicação, desde pouco mais de 5 anos. Disponível em: Disponível em: <http://vimeo.com/14496229>

SÁBAD0 à noite. Diretor: Ivo Lopes. Elenco relevante. Local: Produtora, 2007. 62min. CE/Brasil. 2007.

LONGA vida ao cinema cearense. Diretor: Irmãos Pretti. Elenco relevante. Local: Produtora, 2008. MiniDV, 11min. CE/Brasil. Disponível em: < http://vimeo. com/44767898>

D0CE amianto. Diretor: Guto Parente e Uirá dos Reis. Elenco relevante. Local: Produtora, 2013. HD, 70min. CE/Brasil.

REMINISCENCES of a journey to lithuania. Diretor: Jonas Mekas. Elenco relevante. Local: Produtora, 19711972. (82 min.), color, 16mm. 
WALDEN, diares, notes and sketches. Diretor: Jonas

Mekas. Elenco relevante. Local: Produtora, 1969. (180

min.), color., 16mm. Filmado entre 1964-1968.

LOST, lost, lost, diares, notes and sketches. Diretor:

Jonas Mekas. Elenco relevante. Local: Produtora, 1963.

(180 min.), color. Filmado entre 1949/1963 
Infiltrations and permanence of the cinema

\section{Infiltraciones y permanencias en el cine}

\section{Abstract}

This article establishes relationships between Jonas Mekas films (like Paradise not yet lost, Notes for Jerome, Walden) and Rolls, by Ivo Lopes, and Supermemórias, by Danilo Carvalho, trying to create connections and to update a proposition that before being just a defense of the cinema as a place of retaining fragments of life is a defense of cinema itself. Approaching cinemas, the fragments themselves, transits arise from a movie over the other and so comes the permanence of cinema itself. For this, we take the thesis of survival, as a theoretical framework from Didi-Huberman.

\section{Keywords}

Jonas Mekas. Memory. Film. Contemporary Cinema.

El artículo establece relaciones entre las películas Jonas Mekas, notablemente em Reminiscencias de un viaje a Lituania, Walden, Lost, Lost, Lost y Rollos, de Ivo Lopes, y Supermemórias, de Danilo Carvalho, tratando de crear conexiones y una proposición que antes de ser sólo una defensa del cine como un lugar para retener fragmentos de la vida, hace la defensa del cine. Al acercar esos cines, ellos todos hechos de pequeños fragmentos, lo que surge son los tránsitos de una película sobre la otra y la permanencia del cine mismo. En efecto, adopta la tesis de la supervivencia de las imágenes como un marco teórico, en los termos de Didi-Huberman.

\section{Palabras-Clave}

Jonas Mekas. Memoria. Películas.

Cine Contemporáneo. 


\section{Expediente}

A revista E-Compós é a publicação científica em formato eletrônico da Associação Nacional dos Programas de Pós-Graduação em Comunicação (Compós). Lançada em 2004, tem como principal finalidade difundir a produção acadêmica de pesquisadores da área de Comunicação, inseridos em instituições do Brasil e do exterior.

\section{E-COMPÓS I www.e-compos.org.br I E-ISSN 1808-2599}

Revista da Associação Nacional dos Programas

de Pós-Graduação em Comunicacão.

Brasília, v.17, n.2, mai./ago. 2014.

A identificação das edições, a partir de 2008

passa a ser volume anual com três números.

\section{CONSELHO EDITORIAL}

Afonso Albuquerque, Universidade Federal Fluminense, Brasil Alberto Carlos Augusto Klein, Universidade Estadual de Londrina, Brasil Alex Fernando Teixeira Primo, Universidade Federal do Rio Grande do Sul, Brasil Rio Grande do Sul, Brasi

Ana Gruszynski, Universidade Federal do Rio Grande do Sul, Brasil Ana Silvia Lopes Davi Médola, Universidade Estadual Paulista, Brasil André Luiz Martins Lemos, Universidade Federal da Bahia, Brasi Ângela Freire Prysthon, Universidade Federal de Pernambuco, Brasil Antônio Fausto Neto, Universidade do Vale do Rio dos Sinos, Brasil Antonio Carlos Hohlfeldt, Pontifícia Universidade Católica do Rio Grande do Sul, Brasil Antonio Roberto Chiachiri Filho, Faculdade Cásper Líbero, Brasi Arlindo Ribeiro Machado, Universidade de São Paulo, Brasil Arthur Autran Franco de Sá Neto, Universidade Federal de São Carlos, Brasil Benjamim Picado, Universidade Federal Fluminense, Brasil César Geraldo Guimarães, Universidade Federal de Minas Gerais, Brasil Cristiane Freitas Gutfreind, Pontifícia Universidade Católica do Rio Grande do Sul, Brasil Denilson Lopes, Universidade Federal do Rio de Janeiro, Brasil Denize Correa Araujo, Universidade Tuiuti do Paraná, Brasi Edilson Cazeloto, Universidade Paulista , Brasil

Eduardo Vicente, Universidade de São Paulo, Brasil Eneus Trindade, Universidade de São Paulo, Brasil Erick Felinto de Oliveira, Universidade do Estado do Rio de Janeiro, Brasi Florence Dravet, Universidade Católica de Brasília, Brasil Gelson Santana, Universidade Anhembi/Morumbi, Brasi Gilson Vieira Monteiro, Universidade Federal do Amazonas, Brasil Gislene da Silva, Universidade Federal de Santa Catarina, Brasil Guillermo Orozco Gómez, Universidad de Guadalajara Gustavo Daudt Fischer, Universidade do Vale do Rio dos Sinos, Brasil Hector Ospina, Universidad de Manizales, Colômbia Herom Vargas, Universidade Municipal de São Caetano do Sul, Brasil Ieda Tucherman, Universidade Federal do Rio de Janeiro, Brasil Inês Vitorino, Universidade Federal do Ceará, Brasil Janice Caiafa, Universidade Federal do Rio de Janeiro, Brasil Jay David Bolter, Georgia Institute of Technology Jeder Silveira Janotti Junior, Universidade Federal de Pernambuco, Brasi João Freire Filho, Universidade Federal do Rio de Janeiro, Brasil John DH Downing, University of Texas at Austin, Estados Unidos Ana Carolina Damboriarena Escosteguy, Pontifícia Universidade Católica do

José Afonso da Silva Junior, Universidade Federal de Pernambuco, Brasil José Carlos Rodrigues, Pontifícia Universidade Católica do Rio de Janeiro, Brasil José Luiz Aidar Prado, Pontifícia Universidade Católica de São Paulo, Brasil José Luiz Warren Jardim Gomes Braga, Universidade do Vale do Rio dos Sinos, Brasil Juremir Machado da Silva, Pontifícia Universidade Católica do Rio Grande do Sul, Brasil Laan Mendes Barros, Universidade Metodista de São Paulo, Brasil Lance Strate, Fordham University, USA, Estados Unidos Lorraine Leu, University of Bristol, Grã-Bretanha Lucia Leão, Pontifícia Universidade Católica de São Paulo, Brasil Luciana Panke, Universidade Federal do Paraná, Brasil Luiz Claudio Martino, Universidade de Brasília, Brasil Malena Segura Contrera, Universidade Paulista, Brasil Márcio de Vasconcellos Serelle, Pontifícia Universidade Católica de Minas Gerais, Brasil Maria Aparecida Baccega, Universidade de São Paulo e Escola Superior de Propaganda e Marketing, Brasil Maria das Graças Pinto Coelho, Universidade Federal do Rio Grande do Norte, Brasil Maria Immacolata Vassallo de Lopes, Universidade de São Paulo, Brasil Maria Luiza Martins de Mendonça, Universidade Federal de Goiás, Brasil Mauro de Souza Ventura, Universidade Estadual Paulista, Brasil Mauro Pereira Porto, Tulane University, Estados Unidos Nilda Aparecida Jacks, Universidade Federal do Rio Grande do Sul, Brasil Paulo Roberto Gibaldi Vaz, Universidade Federal do Rio de Janeiro, Brasil Potiguara Mendes Silveira Jr, Universidade Federal de Juiz de Fora, Brasil Renato Cordeiro Gomes, Pontifícia Universidade Católica do Rio de Janeiro, Brasil Robert K Logan, University of Toronto, Canadá

Ronaldo George Helal, Universidade do Estado do Rio de Janeiro, Brasil Rosana de Lima Soares, Universidade de São Paulo, Brasi Rose Melo Rocha, Escola Superior de Propaganda e Marketing, Brasil Rossana Reguillo, Instituto de Estudos Superiores do Ocidente, Mexico Rousiley Celi Moreira Maia, Universidade Federal de Minas Gerais, Brasi Sebastião Carlos de Morais Squirra, Universidade Metodista de São Paulo, Brasil Sebastião Guilherme Albano da Costa, Universidade Federal do Rio Grande do Norte, Brasil

Simone Maria Andrade Pereira de Sá, Universidade Federal Fluminense, Brasi Tiago Quiroga Fausto Neto, Universidade de Brasília, Brasil Suzete Venturelli, Universidade de Brasília, Brasil Valerio Fuenzalida Fernández, Puc-Chile, Chile Veneza Mayora Ronsini, Universidade Federal de Santa Maria, Brasil Vera Regina Veiga França, Universidade Federal de Minas Gerais, Brasil

\section{COMISSÃO EDITORIAL}

Cristiane Freitas Gutfreind I Pontifícia Universidade Católica do Rio Grande do Sul, Brasil Irene Machado I Universidade de São Paulo, Brasil

Jorge Cardoso Filho I Universidade Federal do Reconcavo da Bahia, Brasil / Universidade Federal da Bahia, Brasil

CONSULTORES AD HOC

Adriana Amaral, Universidade do Vale do Rio dos Sinos, Brasil

Alexandre Rocha da Silva, Universidade Federal do Rio Grande do Sul, Brasi Arthur Ituassu, Pontifícia Universidade Católica do Rio de Janeiro, Brasil Bruno Souza Leal, Universidade Federal de Minas Gerais, Brasil Elizabeth Bastos Duarte, Universidade Federal de Santa Maria, Brasil Francisco Paulo Jamil Marques, Universidade Federal do Ceará, Brasil Maurício Lissovsky, Universidade Federal do Rio de Janeiro, Brasil Suzana Kilpp, Universidade do Vale do Rio dos Sinos, Brasil Vander Casaqui, Escola Superior de Propaganda e Marketing, Brasil

EDIÇÃO DE TEXTO E RESUMOS I Susane Barros SECRETÁRIA EXECUTIVA I Helena Stigger EDITORAÇÃo ELETRÔNICA I Roka Estúdio
COMPÓS I www.compos.org.br

Associação Nacional dos Programas de Pós-Graduação em Comunicação

Presidente

Eduardo Morettin

Universidade de São Paulo, Brasil

eduardomorettin@usp.br

Vice-presidente

Inês Vitorino

Universidade Federal do Ceará, Brasil

ines@ufc.br

Secretária-Geral

Gislene da Silva

Universidade Federal de Santa Catarina, Brasil

gislenedasilva@gmail.com 